\title{
IMAGING IN TUBERCULOSIS
}

Prof. V. Subramanian, Professor \& Head

Department of Radiology, Shri Sathya Sai Medical College \& Research Institute, Sri Balaii Vidyapeeth, Nellikuppam, Kancheepuram Dist., Tamil Nadu - 603 108, India.

\section{CECT BRAIN}

Multiple Tuberculomata

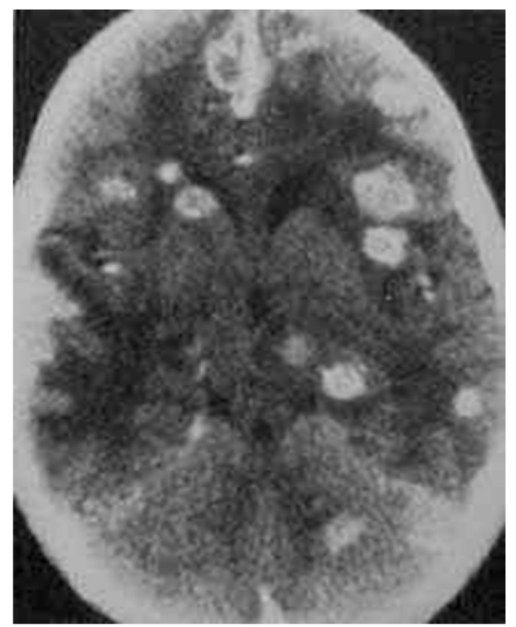

CT BRAIN

Right sided lesion with perilesional edema, compressing the ventricles

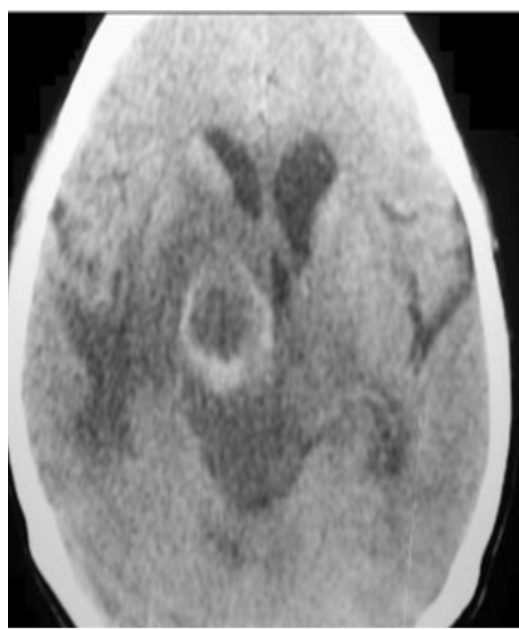

MRI BRAIN WITH CONTRAST

Multiple ring enhancing lesions in Brain

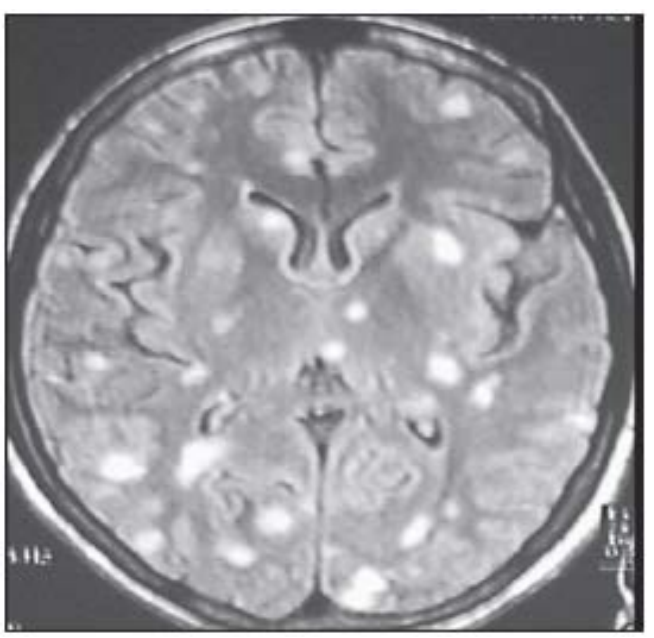

Same patient CXR showing Miliary TB

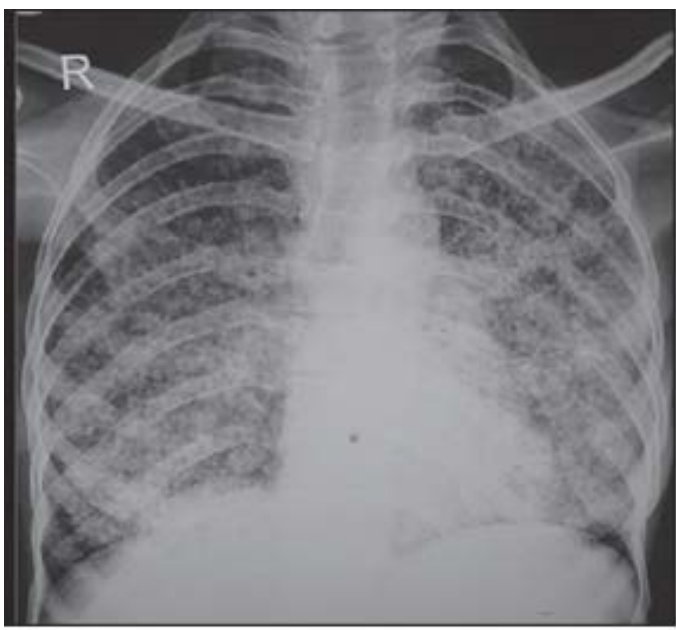




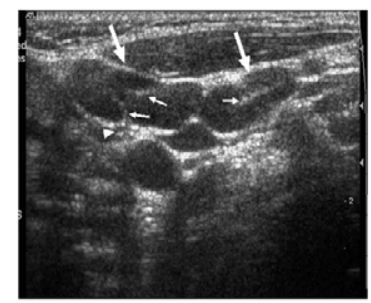

Ultrasound

Neck with enlarged cervical nodes

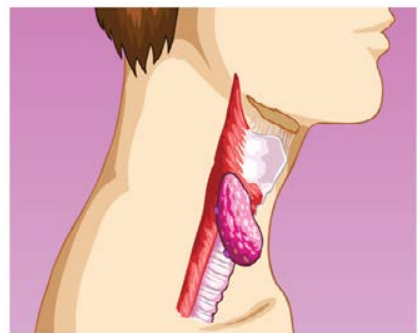

LYMPH NODE

Diagram showing the location of the lymph node

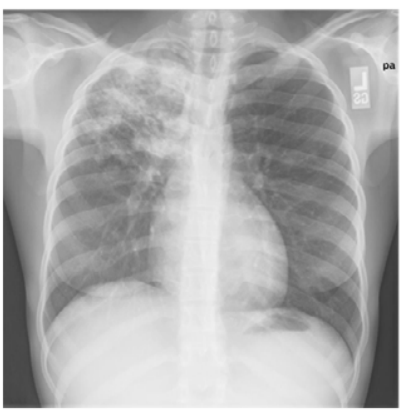

CHEST X-RAY -

Parenchymal lesion in right upper lobe

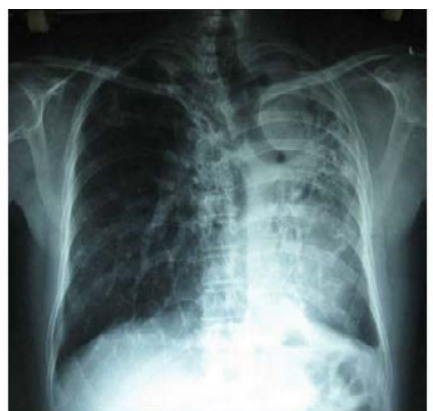

Tracheal and mediastinal shift to left due to fibrosis
CT CHEST - Coronal Reconstruction Mass within the cavity in right upper lobe

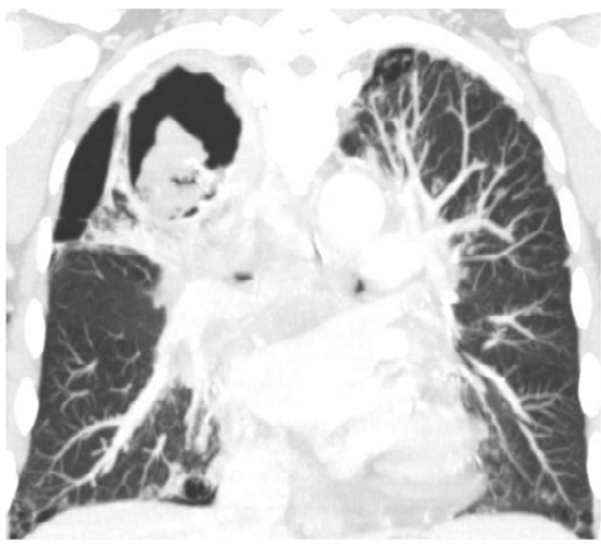

CT CHEST - Intra-cavity fungal ball - Air crescent sign

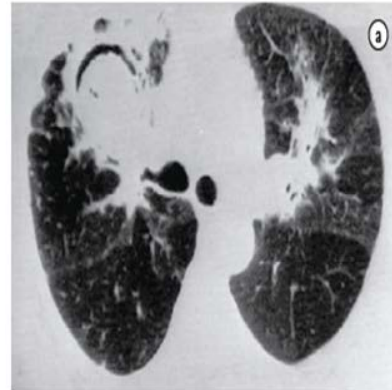

Supine

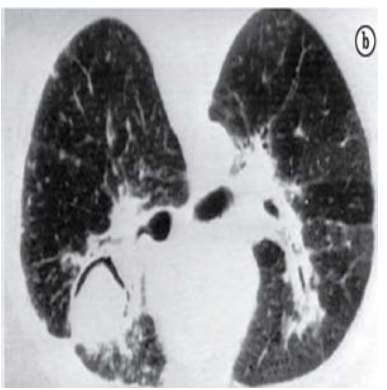

Prone
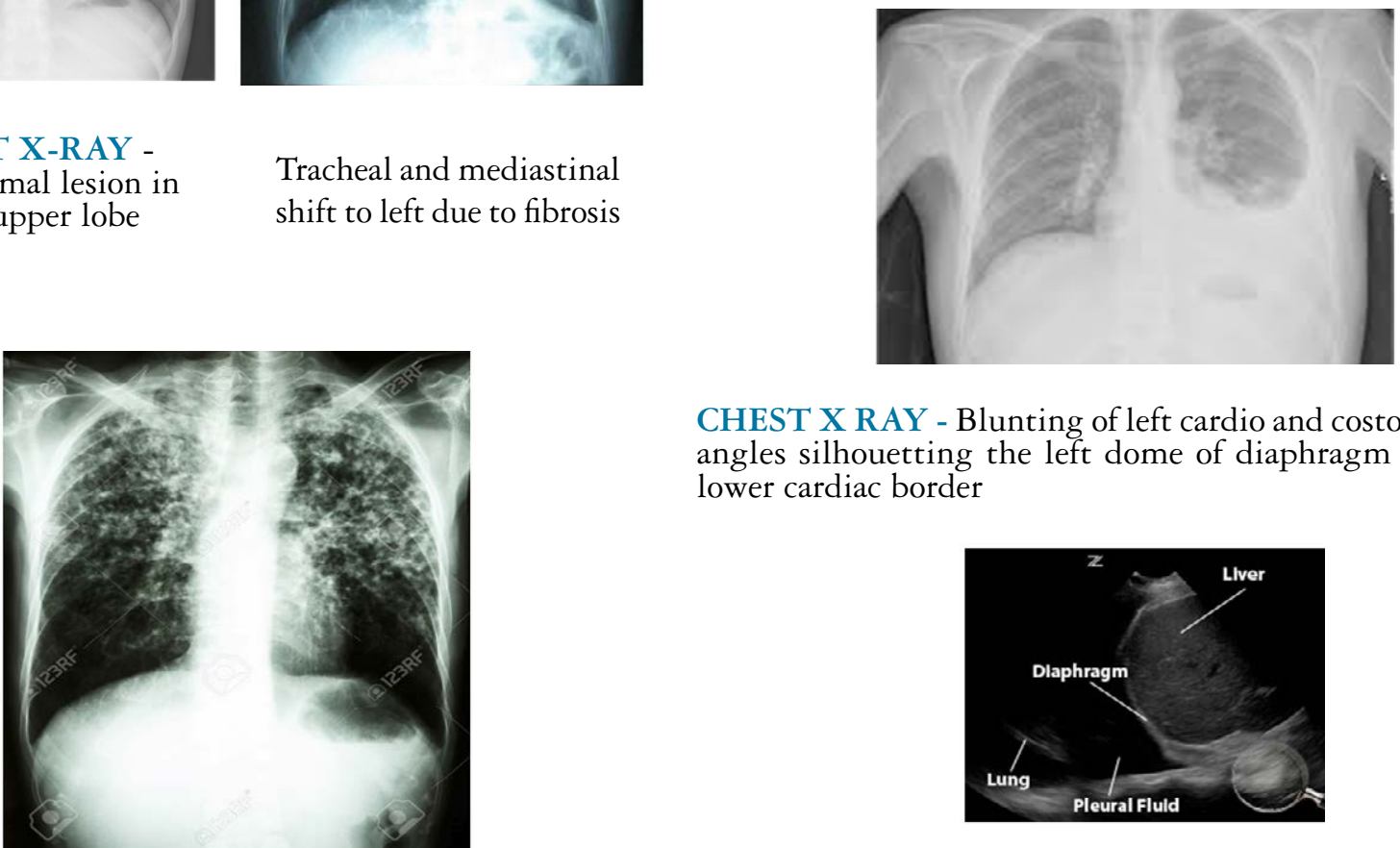

CHEST X RAY - Blunting of left cardio and costo phrenic angles silhouetting the left dome of diaphragm and left lower cardiac border

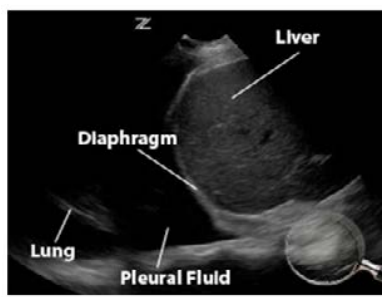

\section{ULTRASOUND}

Right pleural effusion 
CHEST X RAY - Left side pleural calcification

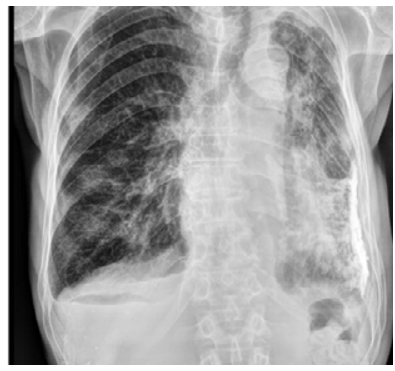

CHEST X RAY - Miliary TB

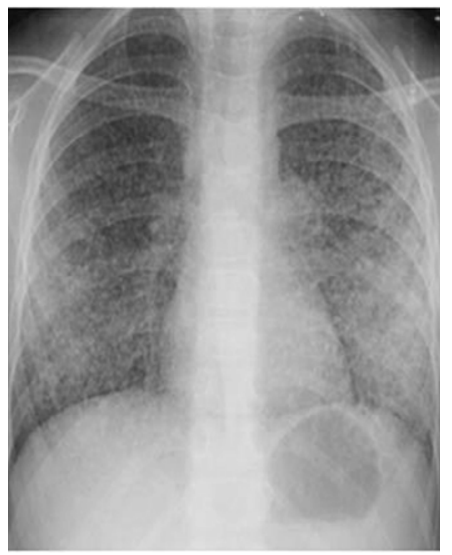

CHEST X RAY - Cavity in right upper lobe

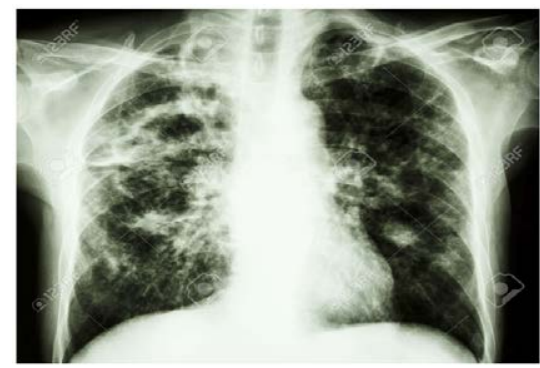

HRCT CHEST - Left upper lobe Bronchiectasis

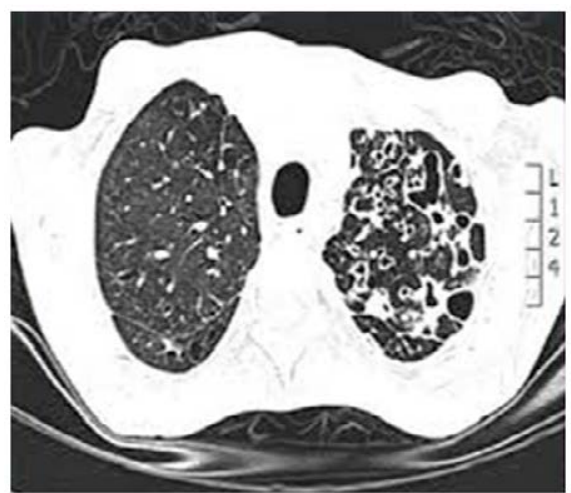

CHEST X RAY-Primary pulmonary infiltrate with right hilar node enlargement

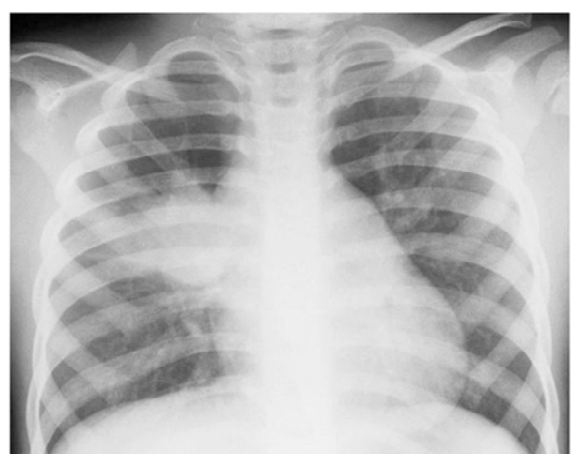

\section{EXTRA PULMONARY TB - C T SCAN}

TB spine with bilateral Psoas abscess $\mathrm{L}>\mathrm{R}$

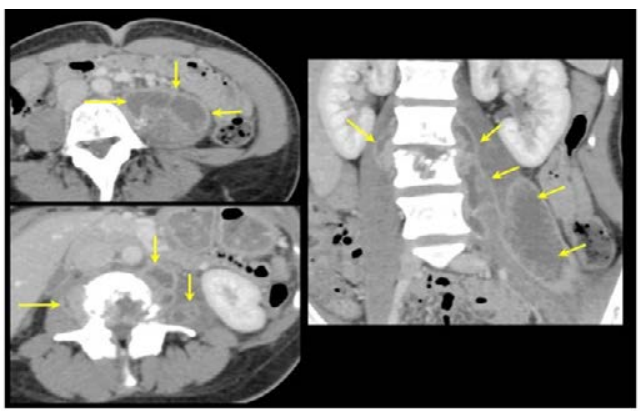

TUBERCULOSIS SPINE - MRI

Wedge compression with retrolisthesis of L4 vertebra

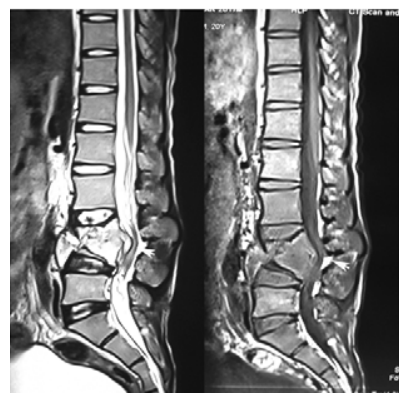

TUBERCULOSIS SPINE - MRI

Wedging with cord compression

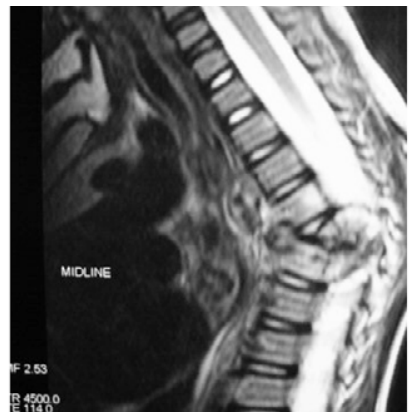




\section{ELBOW JOINT}

Destruction with soft tissue changes

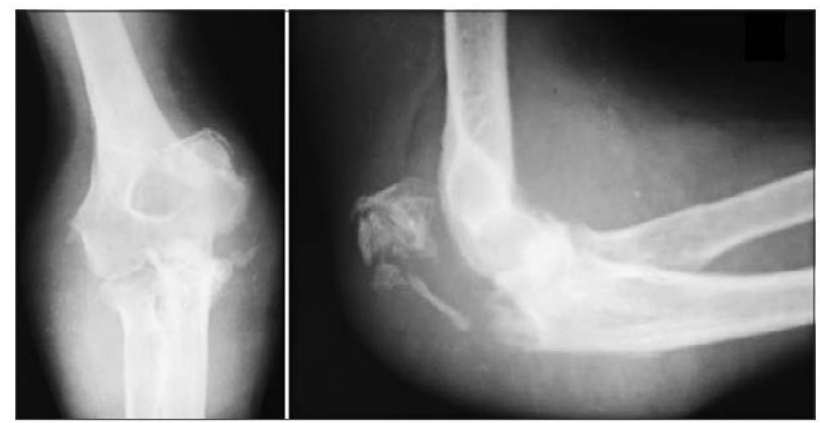

X RAY PELVIS

Tuberculosis affecting the right hip

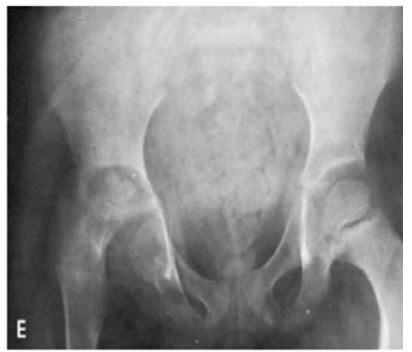

X RAY CALCANEUM

Tuberculosis of calcaneum

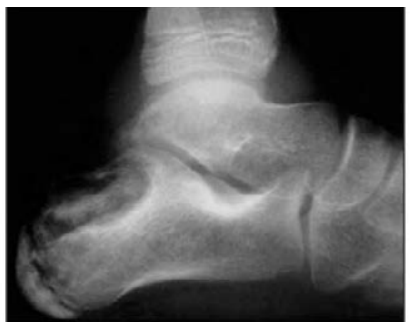

BARIUM ENEMA

Narrowing of the transverse colon

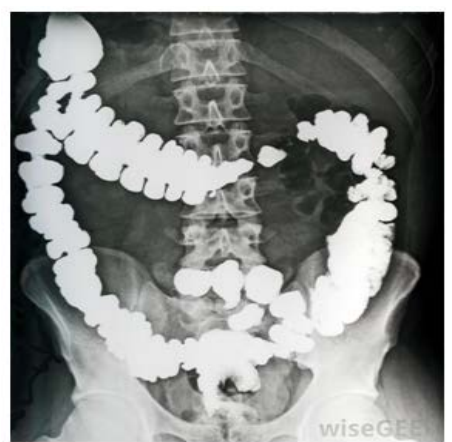

\section{BARIUM MEAL}

Barium study showing ileo-cecal junction lesion.

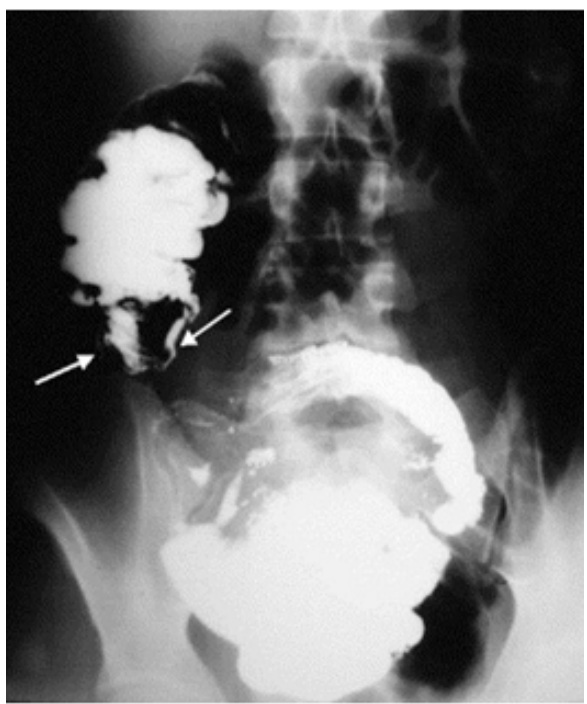

BARIUM MEAL

Terminal ileum thickening due to tuberculosis

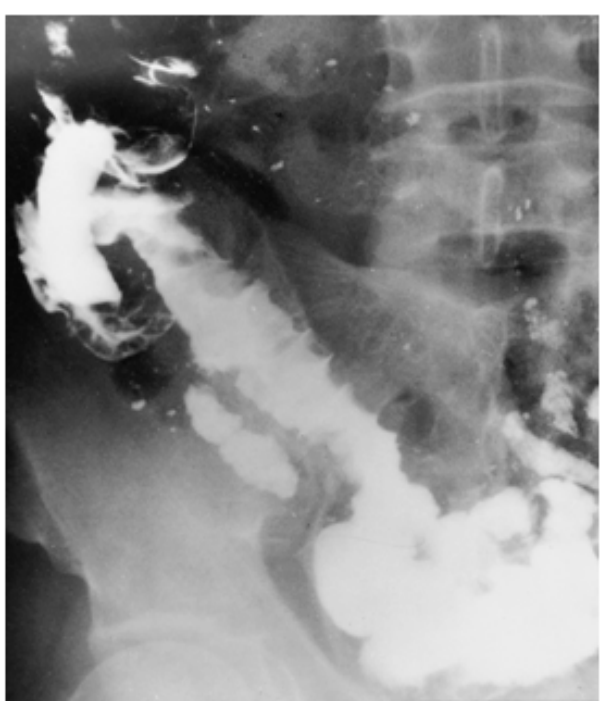

Tuberculosis of Genito Urinary System IVU- Papillary necrosis
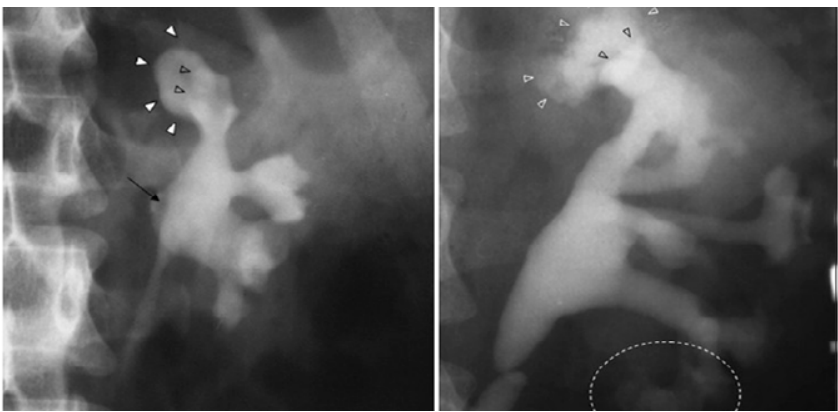


\section{CT SCAN}

Right renal parenchymal calcification

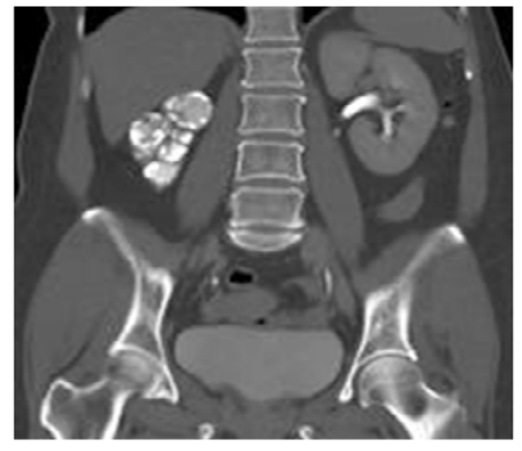

X RAY

Right adrenal calcification

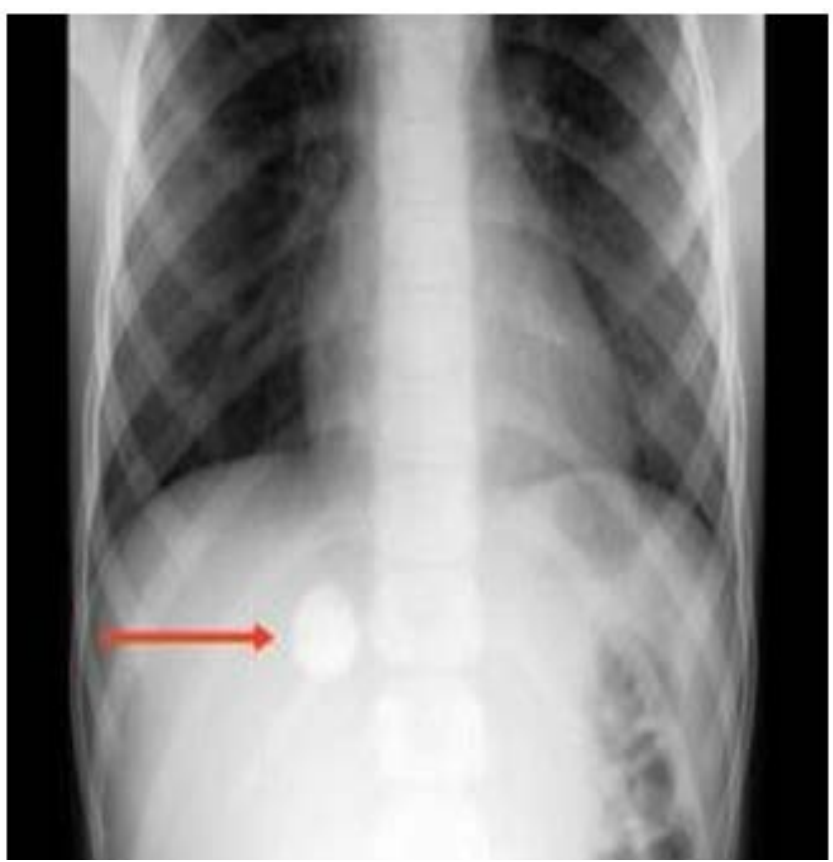

Source : Department of Radiology, SSSMCRI.
HYSTERO SALPINGOGRAM (HSG)

Both fallopian tubes appear rigid with small terminal sacculations.

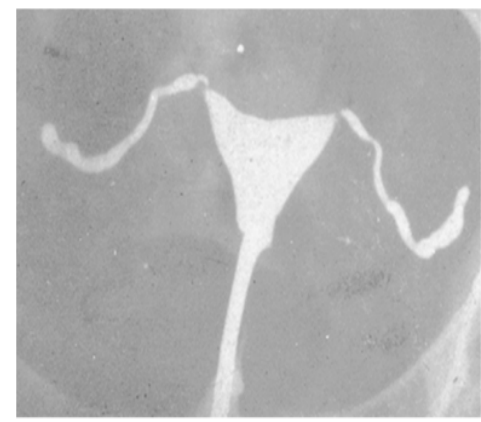

$$
\text { NON CONTRAST CT }
$$

Bilateral adrenal calcification

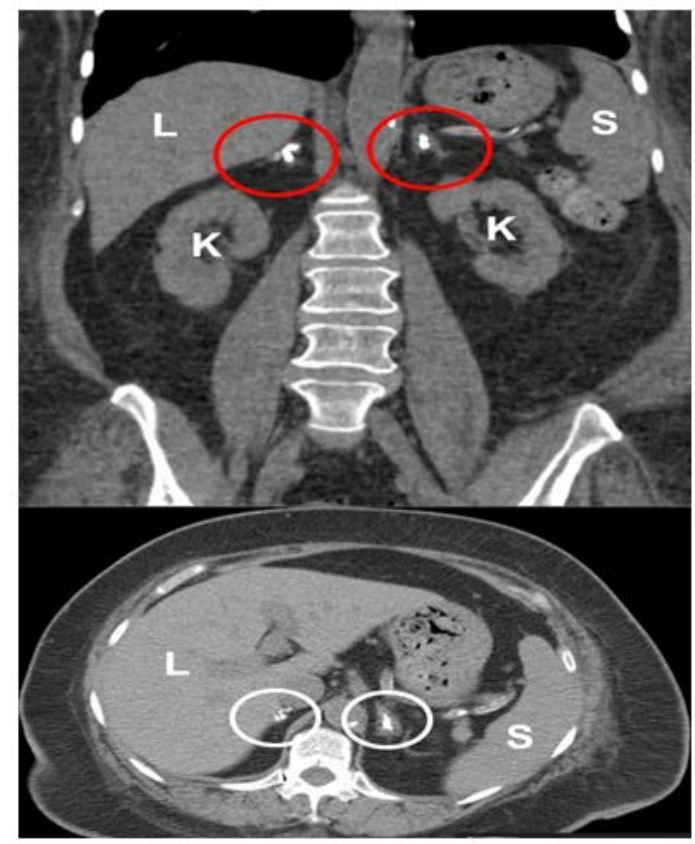

